"Handled logically this could have

\section{been a triumph... instead it is an all}

\section{too familiar shambles."}

\title{
It is all about motivation
}

I am occasionally asked by actors and actresses what motivation their characters have for various lines that I have written for them in plays and the like. It is a bit of a cliché but there is usually a good reason for the question as the performer is attempting to understand their character better and provide an improved performance for the audience.

But motivation often involves finishing the sentence, or at least the sentiment behind it. In acting it is sometimes forgivable, indeed sometimes it adds value for the observer when everything is not spoken or revealed. But there does not seem to be much of a case for it in health care. I have in mind the recent advice issued by the various UK Departments of Health in relation to the single-use of endodontic instruments.

One has to assume that the information is imparted in good faith, since why else would a state department issue such advice (it is advice, note, not guidance or direction). Advice nonetheless that 'dentists are expected to follow'? But the manner in which it was announced and the scientific basis on which it is apparently founded both give rise to suspicions and to distrust. It is probably just poor logistics but the result is that it opens the way to questions over motivation.

Firstly to the manner in which it was announced; it transpires that all policy developments and guidance in relation to vCJD has to be first reported to Parliament before any other communication can take place. This was a commitment made by John Reid when he was Secretary of State for Health and supported by the then current Ministers. This explains why BDA members contacted us the same morning of the announcement asking why the Association had not let them know. We had to reply that it was because we did not know about it either until we heard it on BBC Radio 2. Important as it is that 630 MPs (or however many were in the Chamber that session) are the first to know, presumably patients in surgeries with the radio on and endodontic instruments in their root canals would also think it a matter of some importance. With hindsight, can our elected representatives really believe that this is the best way to deal with matters of health care?

The science on which this advice is based brings forth a further clutch of questions. We are told that, "early results from studies in mice suggest that TSE (Transmissible Spongiform Encephalopathies, the group of prion diseases that include BSE, CJD, vCJD and scrapie) infectivity can be found in dental tissues'. The studies, early results or not, are not published so none of us can assess that risk independently.
On the one hand this may seem reasonable since we are constantly being entreated ourselves to follow best practice as indicated by evidence-based studies. We have to take the Chief Dental Officers' words at face value, since we have no other base on which to judge them, as indeed presumably they have had to take the words of others above them. But on the other hand this is about calculated risk assessment. Someone, somewhere has taken a decision on the basis of what is known to date and the extent to which they assess that to be a threat to the population. Or in this case a 'theoretical' threat. Once again though, we are denied the knowledge of the motivation. Is the advice given on a defensive basis so that if in years to come patients can show that they have contracted a TSE disease from endodontic treatment they will be able to sue the government because it failed to act on the scientific advice of the time? Or is the advice given on the basis that such potential litigation is then passed to the individual dentist? Alternatively, is the advice just on the basis of taking good care of the population? It might be all or any of these but we have to guess and it is the guessing that substantially increases the risk of distrust.

All of this, sadly, obscures what one hopes is the real motivation behind the advice, which is that if there is a risk then it is wise to take sensible precautions. The issues of who pays the additional costs and the environmental questions of reamer and file-mountains all need to be considered in the risk evaluation too. Have they been? Conflicting reports on the possibility or not of financial compensation for those dentists offering NHS dentistry have served only to add further confusion, rumour and annoyance.

The handling of the matter as a whole makes one seriously doubt that any kind of global view has been taken before the advice has been rushed out. We may, as a profession, be accused of starting to get paranoid about having matters forced upon us with little or no consultation, little or no notice and precious little respect for our professionalism but is it really surprising? Handled logically, with proper sequencing this development could have been, should have been, a triumph for good sense, measured response and excellence in health care. Instead it is an all too familiar shambles. How many more will there be?

Stephen Hancocks OBE Editor-in-Chief

DOI: $10.1038 /$ bdj.2007.422 